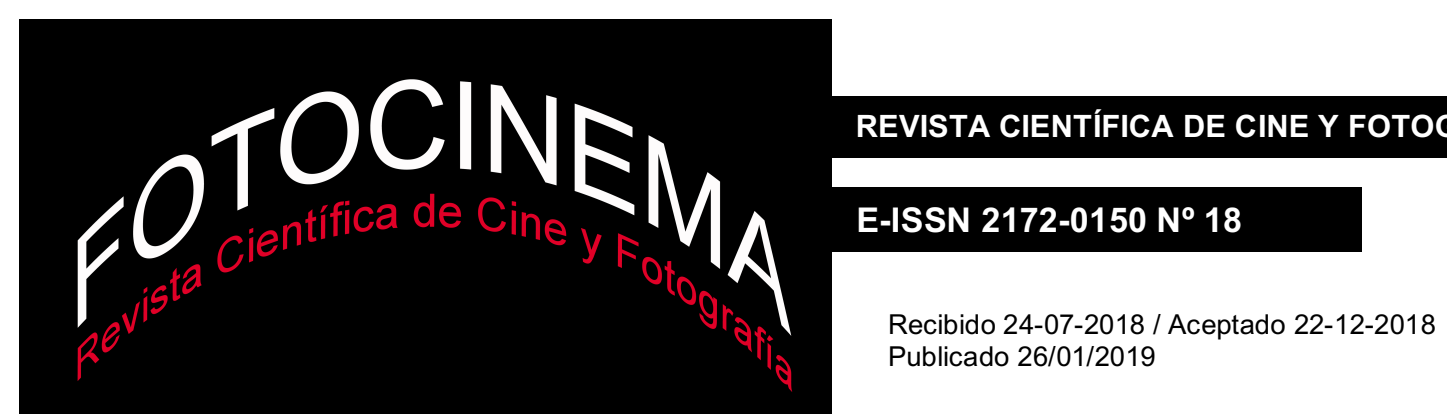

\title{
De música, propaganda y publicidad en el No-Do
}

\author{
The music, propaganda and the No-Do advertising
}

\author{
Rafael Ángel Rodríguez López \\ Universidad de Córdoba, España \\ rafarl@live.com
}

\section{Resumen:}

Convertida ya en una disciplina artística de la comunicación audiovisual, la música se vuelve un instrumento imprescindible para la publicidad y promoción de una imagen, símbolo o concepto publicitario, ayudando a recordar rápidamente el mensaje propagandístico que al medio le interesa que tengamos siempre presente. Por ello, la cinematografía es uno de los espacios audiovisuales que más se beneficia de la utilización del binomio música-imagen como elementos de difusión. En el presente artículo, trataremos de explicar cómo el No-Do utilizó una de las técnicas audiovisuales más empleadas actualmente en el mundo publicitario, el Audio Branding. De este modo, desentrañaremos aquellos recursos formales que, desde un punto de vista musical, fueron utilizados para la promoción del No-Do en las cabeceras de sus Noticiarios. Analizaremos cómo los cambios que se produjeron en las imágenes de dichas cabeceras sufren modificaciones en pro de la conservación de la banda sonora compuesta por Manuel Parada de la Puente, siendo su música la responsable de la durabilidad de la marca No-Do en el tiempo.

\section{Abstract:}

Already transformed into an artistic discipline of audiovisual communication, music has become an essential tool for advertising and image promotion, sing or advertising concept helping to quickly remember the advertising message which media is interested we keep in mind. For it, cinematography is one of the audiovisual media that benefits the most of the use of music-image binomial as dissemination elements. In this article we will try to explain how the No-Do used one the most used audiovisual techniques currently in the advertising world, the Audio Branding. In this way, we will unreveal those formal resources which, from a musical point of view, they were used for the No-Do promotion on their newspaper mastheads. We will see how the changes in the pictures of such mastheads undergo modifications in pro of the conservation of the soundtrack composed by Manuel Parada de la Puente, being his music the responsible for the durability of the No-Do brand over time.

\section{Palabras clave:}

Cinematografía; publicidad; propaganda; imagen; música; Audio Branding.

\section{Keywords:}

Cinematography; Advertising; Propaganda; Image; Music; Audio Branding. 


\section{Introducción}

Raúl Eguizábal establece que la propaganda y la publicidad se encuentran obligadas a convencer o persuadir, buscando un comportamiento o un cambio de actitud hacia una opción política o comercial (Raúl Eguizábal, 2011, p.108). Ambos términos, y centrándonos en el ámbito cinematográfico, se han convertido en dos elementos imprescindibles para que el cine llegue de manera eficaz a la sociedad. Para ello, se nutre de herramientas audiovisuales que expresan, marcan y forman la estructura de aquello que el pase cinematográfico quiere revelar, encontrando en la sincronización y utilización conjunta de la imagen y la música su mayor aliada. La cinematografía, hace un uso cada vez más frecuente de estas herramientas para que los parámetros publicitarios que coexisten en la gran pantalla puedan llegar al máximo número de usuarios/clientes posibles y aunque la funcionalidad de estos instrumentos comunicativos se ha ido especializando, su empleo fue aplicado en épocas anteriores a la actual.

Si nos adentramos en los años 40, donde una de las formas de entretenimiento e información audiovisual en nuestro país se descubría en las salas de cine con las reproducciones de No-Do, nos encontramos con que, sin poseer los actuales medios de divulgación (televisión, radio o internet), el régimen se valió de la imagen y la música como elementos publicitarios, estableciéndose un enlace entre ambos mundos que, a partir de entonces, estarán destinados a entenderse durante mucho tiempo. Por este hecho, el No-Do, utilizado como propaganda del régimen desde 1943 hasta 1981 y convertido en la actualidad en un archivo histórico fundamental para nuestra memoria colectiva, representa un punto de partida inmejorable para comprender y conocer la utilización de la imagen y la música como recursos publicitarios.

Para garantizar la difusión y la durabilidad en el tiempo de la marca No-Do desde su primer pase cinematográfico hasta su reproducción en las plataformas web existentes hoy día, los Noticiarios y Documentales manejaron una de las técnicas audiovisuales más empleadas actualmente en el mundo publicitario, el Audio Branding. En este sentido, trataremos de dar cuenta de la significación e importancia del concepto de Audio Branding como herramienta publicitaria, y 
de su repercusión en la cinematografía en conjunción con la música compuesta por Manuel Parada de la Puente para las cabeceras de los Noticiarios de No-Do.

En lo que sigue, demostraremos cómo las imágenes que componen dichas cabeceras sufren diversas modificaciones en pro de la música con el fin de utilizar, como venimos diciendo, la música y la imagen como reclamo propagandístico a la vez que publicitario. Para llevar a cabo nuestro propósito, realizaremos a continuación un análisis comparativo de las diez modificaciones que sufrieron las cabeceras de los Noticiarios del No-Do durante toda su emisión, en relación al binomio que hemos mencionado con anterioridad.

\section{Breves apuntes sobre el Audio Branding}

Tal y como señala Toni Guijarro y Clara Muela, la música, las voces, o los efectos sonoros, tienen unas funciones concretas y diferentes. Cada elemento representa unos significados específicos que, bien encajados unos con otros, aportan la credibilidad y la eficacia que cualquier mensaje desea conseguir. (Guijarro \& Muela, 2003, p. 23). Estas herramientas audiovisuales se han convertido para el medio publicitario, casi, en imprescindibles. Son instrumentos comunicativos que ayudan a la publicidad a que determinados mensajes se retengan con mayor facilidad, de tal manera que el cliente, de forma inconsciente, recuerda la imagen, símbolo o concepto publicitario, al instante.

Componer el diseño sonoro de una determinada imagen promocional para mejorar exponencialmente su comunicación con el cliente, se ha convertido en una disciplina artística, y por qué no decirlo, científica, que ha sido bautizada como Audio Branding (marca). Georg Spehr lo describe como un proceso de conexión emocional entre el transmisor y el receptor a través del sonido, un pilar asociativo para el reconocimiento, la comunicación de mensajes, la transferencia y consolidación de imágenes (Georg Spehr, 2009, p. 27).

Aunque el término es relativamente nuevo, el uso de un sonido concreto, como elemento o recurso comunicativo, ya fue empleado con anterioridad hasta convertirse hoy en un componente artístico notable para la comunicación, publicidad y propaganda. Merece la pena subrayar la definición que realiza Ubik 
Media, agencia especializada en la investigación y el desarrollo de la comunicación, referente al Audio Branding en unas de sus publicaciones web:

El audio es una herramienta de altísima eficiencia, durabilidad y sugestión en el ámbito de la publicidad ya que tiene la capacidad de vincular en nuestra memoria sonidos con experiencias, sensaciones, emociones y recuerdos. [...] evocando, sin uno saberlo, una cascada de sensaciones [...] Las grandes marcas son conscientes de ello y por eso sacan el máximo provecho de esta herramienta. Aunque algunas con más éxito que otras. En efecto, ciertos sonidos pueden provocar, en el oyente, el efecto contrario al deseado, generando más aversión que simpatía (Ubik Media, 2013).

De estas palabras podemos deducir que el objetivo del Audio Branding no es otro que activar el recuerdo de la imagen proyectada en el espectador y oyente, ahora convertidos en clientes, los cuales reciben muchos de los sonidos, melodías y efectos sonoros digitales que se asocian a una determinada marca, símbolo, evento o concepto publicitario para su promoción. De esta forma, los medios publicitarios y de comunicación crean y actualizan composiciones musicales muy estudiadas y elaboradas para llegar al máximo número de usuarios.

En este sentido, intentando establecer el origen etimológico de la palabra Audio Branding, daremos un salto hacia atrás en el tiempo para poder comprender de dónde procede el uso del sonido como elemento propagandístico e identificativo. Durante siglos, algunos instrumentos sonoros, como las campanas, eran empleados como medio comunicativo. El timbre de estos instrumentos a diferentes alturas se utilizaba para el reconocimiento instantáneo de un acontecimiento, provocando sonidos fácilmente identificables por aquellos que las escuchaban, como puede ser el llamamiento a misa, una alarma de incendio o una indicación horaria, usos del sonido que tenemos muy presentes en nuestro día a día y que juegan un papel muy importante en diversas culturas.

Otro elemento musical, con un poder para la comunicación y la publicidad más que sobresaliente a la hora de abordar nuestro estudio, son las fanfarrias. Con una importancia capital, este tipo de piezas musicales compuestas por instrumentos de metal y a veces acompañados de la percusión $u$ otros instrumentos, se han convertido en un componente comunicativo imprescindible para complementar una determinada imagen. Además, si extrapolamos su 
empleo a la actualidad, comprobamos que siguen siendo muy utilizadas en el ámbito cinematográfico.

Las grandes productoras de cine siguen recurriendo a esta composición musical para acompañar su imagen corporativa y dar comienzo a ese pase cinematográfico que todos esperamos. Entre ellas se encuentran la Waner Bross y la 2oth Century Fox de los años cuarenta, y posteriormente la Universal Pictures desde $1941^{1}$. Actualmente, todas estas compañías cinematográficas utilizan las fanfarrias como elemento comunicativo, y además, introducen algunos efectos sonoros digitales para apoyar y caracterizar elementos concretos de la imagen. De este modo, la sincronización entre la imagen y la música se vuelve imprescindible para comunicar y difundir todos los elementos que en la pantalla concurren para ayudar a que el mensaje publicitario de la marca sea reconocido mediante su música.

Como veremos en lo que sigue, Manuel Parada de la Puente adopta estas formas de comunicación mencionadas con anterioridad para construir la melodía corporativa del No-Do, entendiendo su trabajo no solo como compositor, sino como responsable publicitario y comunicativo.

\section{La imagen de los Noticiarios de No-Do al servicio de la música}

No es casualidad que nos encontremos con una creación musical donde predomina la brillantez, el vigor y la energía de los instrumentos de viento, en la que trompas, trompetas y trombones, sus grandes protagonistas, acompañados con frecuencia de la fuerza percusiva, sean los conductores de la imagen de los Noticiarios de No-Do. Se trata de establecer un intento de semejanza con las grandes cabeceras cinematográficas que se reproducían al otro lado del mundo, en América. Quizás porque las grandes productoras de cine americano estaban haciendo uso de las fanfarrias como elemento propagandístico y publicitario de su imagen corporativa, Manuel Parada² las tomara como modelo.

\footnotetext{
${ }^{1}$ Universal Pictures se fundó en 1912, pero no fue hasta el 1941 cuando utilizaron la música para acompañar a su imagen corporativa.

${ }^{2}$ Laura Miranda proporciona información de cómo el compositor llego a ser seleccionado para crear la música de los Noticiarios. Apuntes encontrados en su más que completa investigación sobre Manuel Parada de la Puente: "Parada compuso previa convocatoria de concurso nacional, la música de la cabecera del No-Do (1943), imagen musical predilecta del nuevo régimen”. (Laura
} 
Desde 1943 hasta 1981 fueron reproducidas 1957 cabeceras de Noticiarios que daban paso a la representación de diversos temas que reflejaban de algún modo, los acontecimientos que ocurrían en la sociedad española, aunque de manera sesgada. Así, No-Do se convierte en una revista de entretenimiento que no modificó su motivo musical en cuarenta años. Este hecho convierte a la música en un aspecto publicitario determinante para el Noticiario.

De modo que antes de abordar las características más representativas de los cambios en su imagen y su música, creemos conveniente realizar la siguiente lista explicativa con los datos de las diez modificaciones que encontramos en los Noticiarios, desde el primero emitido en 1943 al último en 1981, estableciendo así, la fecha exacta, el número de No-Do y el número de modificación realizada:

\begin{tabular}{|c|c|c|}
\hline Fecha & Número No-Do & No de Modificación \\
\hline 4/1/1943 & $\mathrm{N}^{0} 1$ & 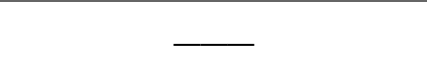 \\
\hline 22/2/1943 & $\mathrm{N}^{0} 8$ & $1^{\mathrm{a}}$ Modificación \\
\hline 3/1 /1944 & $\mathrm{N}^{0} 53 \mathrm{~A} / \mathrm{B}$ & $2^{\mathrm{a}}$ Modificación \\
\hline 27/11/1944 & $\mathrm{N}^{0} 100$ & $3^{\text {a }}$ Modificación \\
\hline 3/10/1960 & $\mathrm{N}^{0} 926 \mathrm{~A} / \mathrm{B} / \mathrm{C} 3$ & $4^{\mathrm{a}}$ Modificación \\
\hline $15 / 4 / 1963$ & $\mathrm{~N}^{0} 1058 \mathrm{~A} / \mathrm{B} / \mathrm{C}$ & $5^{\mathrm{a}}$ Modificación \\
\hline $1 / 1 / 1968$ & $\mathrm{~N}^{0} 1304 \mathrm{~A} / \mathrm{B}$ & $6^{\mathrm{a}}$ Modificación \\
\hline 7/10/1968 & $\mathrm{N}^{\mathrm{O}} 1344 \mathrm{~A}$ & $7^{\mathrm{a}}$ Modificación \\
\hline $7 / 10 / 1968$ & $\mathrm{~N}^{\mathrm{o}} 1344 \mathrm{~B}$ & $8^{a}$ Modificación \\
\hline 3/1/1972 & $\mathrm{N}^{0} 1513 \mathrm{~A} / \mathrm{B}$ & $9^{a}$ Modificación \\
\hline 20/6/1977 & $\mathrm{N}^{0} 1795 \mathrm{~A} / \mathrm{B}$ & $10^{\mathrm{a}}$ Modificación \\
\hline
\end{tabular}

El sentido musical-publicitario que propone el compositor en la sintonía de los Noticiarios se basa en el uso subordinado de la imagen con respecto a la música, hecho un tanto insólito si tenemos en cuenta que en las producciones incluso de

Miranda, 2011, p. 135).

3 El número de catalogación $C$ aparece el No-Do no 926 y se mantiene hasta el no 1255 del 23 de 1967. 
la actualidad, es frecuente que la música se encuentre al servicio de la imagen. Como consecuencia, nos encontramos ante un trabajo de montaje a la inversa, en el que juegan con las imágenes en función de los cambios musicales compuestos por Parada para que cada uno de los elementos cinematográficos de la imagen que en el Noticiario confluyen, estén sincronizados con la música, siendo este recurso sumamente importante para la difusión publicitaria del No-Do.

Estos cambios tienen como objetivos principales, por un lado, que el plano final de la cabecera que muestra el número del Noticiario, sea sincronizado con la música notada por Parada, y, por otro lado, establecer este binomio de imagen y música como el elemento publicitario del No-Do más importante.

En este sentido, durante el análisis musical de la partitura manuscrita de su compositor, encontramos en la cabecera un elemento musical que se repite constantemente en el último plano cinematográfico que muestra el número de No-Do.

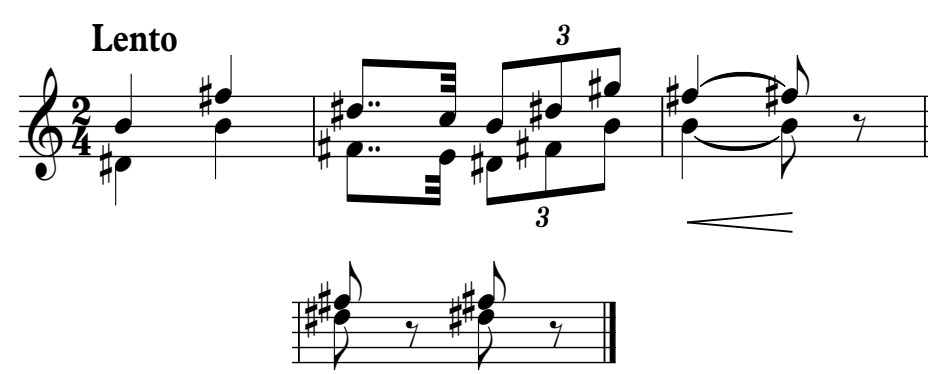

F1. Notación de Manuel Parada de la Puente. Transcripción de los compases4 interpretados por trompas y utilizados para el último plano del Noticiario que muestra el número de No-Do, 2018. (C) Rafael Ángel Rodríguez López.

A pesar de que Parada escribió estos cuatro compases para ser interpretados juntos al final de cada proyección del Noticiario, desde la cabecera $n^{0} 1$ de 1943 hasta la $\mathrm{n}^{0} 925$ del 26 de septiembre de 1960, solo son utilizados los tres primeros compases del motivo 5 musical final (F1), posteriormente, desde la cabecera $\mathrm{n}^{\mathrm{o}}$ 926 del 3 de octubre de 1960, hacen uso del cuarto compás, dos acordes musicales que se repiten sincronizados con el último plano del Noticiario hasta el final de

\footnotetext{
4 El cuarto compás, aunque solo muestra la interpretación de las trompas, el maestro Parada utiliza el tutti orquestal para interpretar la última cadencia. Fuente: Biblioteca Nacional de España, partitura manuscrita de Manuel Parada de la Puente.

5 Llamamos motivo a la parte rítmica y melódica más pequeña de una composición sonora, el cual, puede derivar en los temas musicales más grandes de la construcción musical.
} 
su emisión en 1981. El hecho de que cada fotograma, plano o secuencia de la cabecera del Noticiario sea puesto en un determinado momento, se debe a la sincronización de los cuatro compases expuestos anteriormente con los planos finales, música que bien podríamos considerar su funcionamiento como un Audio Branding publicitario.

De tal modo, desarrollaremos estos aspectos mencionados anteriormente en el siguiente análisis comparativo de las modificaciones encontradas en la cabeceras de los Noticiarios. Por consiguiente, nos introduciremos a continuación en el análisis de su imagen y su música, desentrañando el funcionamiento de sendos elementos como medio propagandístico y publicitario, siendo la música quién responda al porqué de estos cambios producidos en la imagen hasta el final de su emisión. Para ello, se han consultado los elementos que componen la banda sonora establecidos por M. Ángeles Martínez y Antonio Gómez en su manual de análisis aplicado a la cinematografía. Asimismo, y basándonos en el método elaborado por Ana Melendo7, trataremos de establecer la sincronización musical con los registros de la imagen cinematográfica: el semiótico, el fotográfico y el imaginario. En el citado método podemos encontrar, y como su propia autora indica, una recopilación, interpretación y explicación de otros estudios de la imagen cinematográfica (Ana Melendo, 2011, p. 6). Todo ello necesario para comprender el objetivo publicitario del No-Do.

\section{Análisis comparativo}

Con la finalidad de confeccionar una exposición más clara, realizaremos un estudio de las modificaciones que tuvieron lugar en los Noticiarios, por un lado, $\operatorname{los} n^{o} 1,8,53,100$ y 926, y por otro lado, los $n^{o} 1058,1304,13344 A, 1344 B y$ 1513. Estos últimos serán analizados individualmente ya que no guardan relación con sus antecesores en la imagen, pero sí en la música. Asimismo, debemos resaltar que los fotogramas presentados a continuación, no han sufrido ningún tratamiento en la imagen por nuestra parte, mostrando capturas totalmente

\footnotetext{
${ }^{6}$ Martínez, Ma A. \& Gómez, A. (2015). La imagen cinematográfica: manual de análisis aplicado. Madrid: Síntesis.

7 Melendo, A. (2011). Introducción al análisis cinematográfico. Córdoba: UCO.
} 
originales de la Filmoteca Española. Es por ello, que algunos planos difieren de otros en color.

El 4 de enero de 1943 se emite la primera cabecera del Noticiario. La estructura presentada por esta primera cabecera supondrá la base en cuanto a forma y temática para las cabeceras posteriores hasta su completa modificación el 15 de abril de 1963 en el $n^{0}$ de Noticiario 1058. Así, los $n^{\circ} 8, n^{0} 53$ y no 100 , contienen cambios mínimos en su imagen, montados con la finalidad de que los últimos compases musicales compuestos por Parada (F1), no pierdan su sincronía con el último plano.

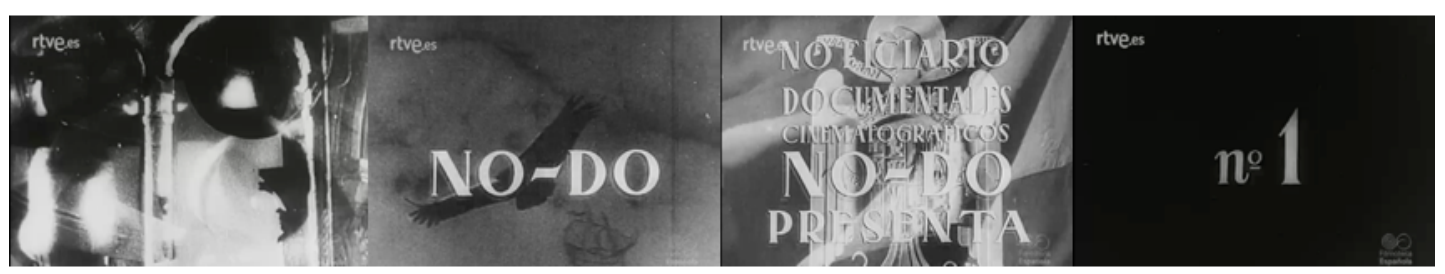

F2. Cabecera No-Do no 1, 4 de enero 1943. Filmoteca Española.

Con una duración de 42 segundos es la cabecera más larga emitada en 40 años. Da comienzo, con una escenografía artificial, una secuencia de campanas en movimiento en representación de la iglesia. Este movimiento es conseguido gracias al montaje de planos superpuestos, además, introducen un sonido diegético grabado y montado, el cual no aparece en la partitura manuscrita del compositor. Acto seguido, aparecen de forma consecutiva, el plano del águila, en representación del estado, y el logotipo del No-Do (Noticiarios, Documentales Cinematográficos, No-Do, Presenta), exhibiendo un fondo que contiene el escudo y la bandera nacional. Toda esta secuencia es acompañada por la música de Parada y sincronizada a la perfección por los montadores de No-Do para que la aparición de la palabra Presenta, sea apoyada por el tutti orquestal. Por ende, ofrecen el sostén musical de toda la orquesta a esta palabra, la cual precede al logotipo del No-Do, Noticiarios y Documentales. De esta forma, toda la música y planos que acontecen en esta cabecera son enlazados con una finalidad, que los últimos compases (F1) de la banda sonora se vuelvan a sincronizar con la secuencia final que muestra nuevamente el número de No-Do.

Si observamos las modificaciones de las cabeceras sufridas en el Noticiario $\mathrm{n}^{0} 8$ del 22 de febrero de 1943 (F3), no 53 A/B del 3 enero de 1944 (F3) y el no 100 del 27 de noviembre de $1944\left(F_{3}\right)$, pertenecientes a la $1^{\mathrm{a}}, 2^{\mathrm{a}}$ y $3^{\mathrm{a}}$ modificación 
respectivamente, podemos comprobar cómo en solo un año la cabecera se ve afectada por tres variaciones en su imagen, donde encontramos aspectos muy llamativos teniendo como responsable de estos cambios a la música.

En la siguiente imagen que a continuación se expone, veremos de forma detallada cuáles son los planos que cambian y la razón de ello. Para entender mejor el análisis llevado a cabo, tendremos que visionar la siguiente imagen en fila y en horizontal. De modo que podamos ver una secuencia entera de cada cabecera.

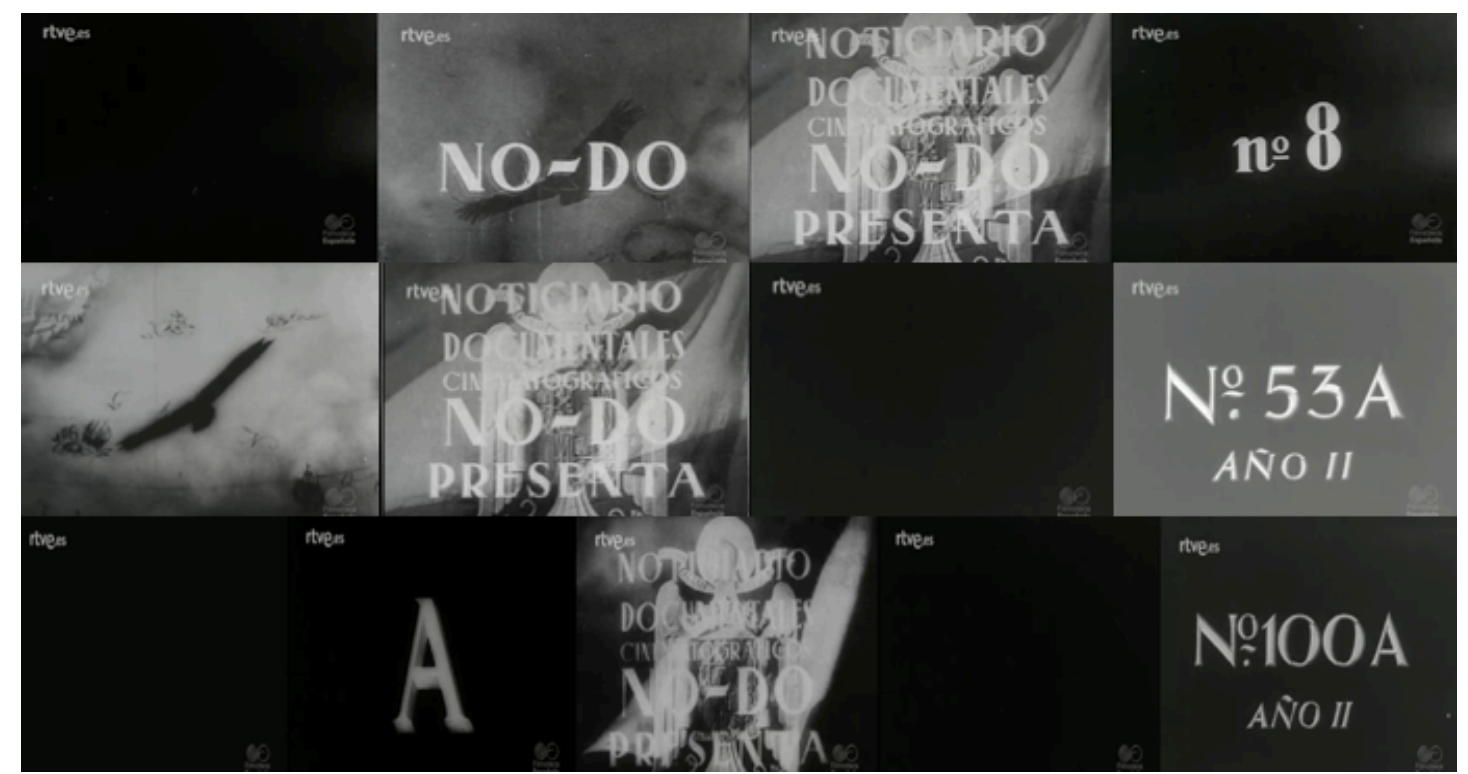

F3. Cabecera No-Do $n^{o} 8,22$ de febrero $1943,1^{a}$ mod. Cabecera $n^{o} 53$ A/B, 3 enero de 1944, $2^{a}$ mod. Cabecera $n^{\circ} 100,27$ de noviembre de 1044, $3^{\text {a }}$ mod. Filmoteca Española.

El primer aspecto que nos llamó la atención es la duración de las nuevas cabeceras, 12 segundos menos con respecto a la primera (F2). Esto es un hecho muy relevante ya que, si la banda sonora no sufre modificación, ¿cómo pueden introducir la misma duración musical en 12 segundos menos de secuencia? Encontramos la respuesta en la sincronización del último motivo musical (F1) de la banda sonora, el cual acompaña al plano final que muestra el número de Noticiario. Para ello, añaden un fundido en negro que se hace casi indispensable para que este objetivo publicitario se cumpliera. En primer lugar, en el Noticiario no 8 (F3), podemos observar cómo el fundido en negro, de 1 segundo de duración, sirve de apertura para la cabecera. Es aquí donde solo se escuchan las primeras notas musicales de las trompetas, suprimiendo, además, toda la percusión principal que sonaba al comienzo del Noticiario $n^{0} 1$ (F2). En segundo lugar, en la cabecera $\mathrm{n}^{0} 53 \mathrm{~A}(\mathrm{~F} 3)$, el plano en negro es cambiado al final de la secuencia, 
el cual tiene una duración de 4 segundos y donde solo se escucha el tutti orquestal de Parada. La razón de este cambio camina por dos vertientes: por un lado, se sincroniza la música con el plano principal del águila, y, por otro lado, con la introducción del fundido en negro consiguen nuevamente que el motivo musical (F1) más característico se sincronice con la última secuencia.

Este hecho, visto en las primeras modificaciones de las cabeceras $\mathrm{n}^{\circ} 8 \mathrm{y} \mathrm{n}^{\mathrm{0}} 53 \mathrm{~A}$, ya presagiaba lo que sería un montaje cinematográfico poco usual, en el cual la imagen se subordina a la música con el objetivo de sincronizar el último plano con el motivo final de la música de Parada.

Incluso, en la $3^{\mathrm{a}}$ modificación de la cabecera que se realiza solo 10 meses más tarde, comprobamos que el sistema de introducir el plano en negro es añadido por partida doble, al comienzo y al final de la cabecera. De hecho, la cabecera $\mathrm{n}^{\mathrm{o}}$ 100 (F3) es la primera que aporta el número de catalogación en su imagen al comienzo del Noticiario. El introducir nuevos planos y no modificar la música, crea para los montadores la problemática de la sincronía. Para resolverlo, acuden al fundido en negro situado, en primer lugar, justo al inicio de la cabecera donde solo se escuchan las primeras notas de las trompetas, y, en segundo lugar, antes de la aparición del último plano del Noticiario, ocupando 3 segundos donde la música realiza su cadencia final para posteriormente volver a sincronizar el número de No-Do con el motivo musical (F1).

Destacar, que los planos acontecidos en estas cabeceras son modificados en su aparición, y que la sincronización con la música varía en todos ellos debido a la supresión e introducción de nuevas imágenes. Con ello, pierden simultaneidad durante el desarrollo de la cabecera ocasionando que ninguna articulación, cambio de ritmo, tutti orquestal o cualquier otra característica musical reseñable, se sincronice de manera precisa con las imágenes (F3). En cambio, ganan a la hora de mostrarnos una imagen vinculada a una música concreta, consiguiendo de esta forma un recurso publicitario y comunicativo muy poderoso en el espectador y oyente.

Asimismo, debemos comentar otro aspecto cinematográfico significativo que ocurre en estos primeros arranques del Noticiario. El plano de las campanas (F2), que en el primer No-Do eran simbolizadas, fueron suprimidas en las demás cabeceras quedando la figura de la iglesia sin representación en el No-Do y no 
volviendo aparecer hasta 1963. Sin olvidar que la iglesia era uno de los grandes pilares del régimen, no entendemos muy bien su eliminación y su posterior aparición 20 años más tarde. Así pues, todos los cambios acontecidos en la cabecera $n^{0} 100$ de $1944\left(F_{3}\right)$ se mantienen hasta la $4^{a}$ modificación realizada el 3 de octubre de 1960, perteneciente al Noticiario nº 926 A/B/C (F4).

Teniendo en cuenta que la siguiente cabecera del Noticiario objeto de este análisis, dura la mitad que sus antecesoras, 17 segundos, ya sabemos a priori que la música se verá afectada. Han tenido que pasar 16 años para ver un nuevo cambio en la cabecera de No-Do, concretamente en el no 926 A/B/C donde las modificaciones son realizadas tanto en su imagen como en su música.

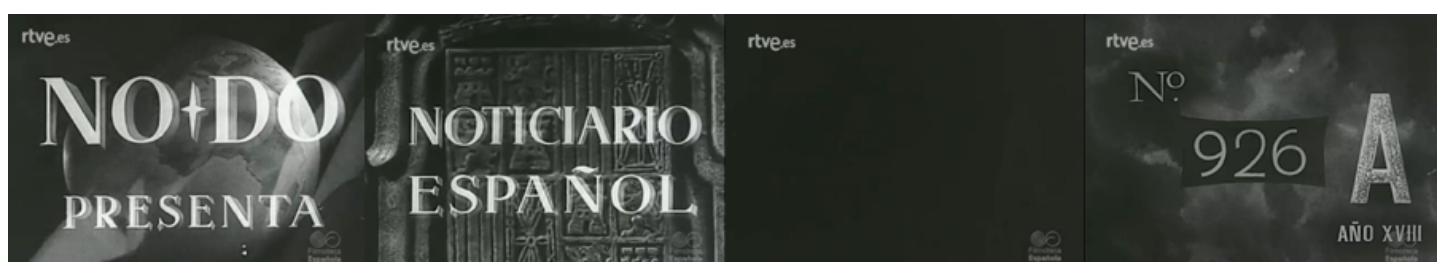

F4. Cabecera No-Do $n^{o} 926$ A/B/C, 3 de octubre 1960, $4^{\text {a }}$ mod. Filmoteca Española.

Sorprende comprobar la supresión, por un lado, del águila, y por otro lado, de la catalogación (A/B/C) al inicio de la cabecera, ahora incluido en la secuencia final con el número de No-Do. Además, estos planos suceden de forma consecutiva y con una velocidad de reproducción el doble de rápida. Al mismo tiempo, encontramos tres nuevos diseños en la imagen, en primer lugar, el mapa cartográfico es sustituido por la bola del mundo, provocando así más profundidad y movilidad a la secuencia, y, en segundo lugar, cambia la imagen corporativa del No-Do, ahora de mayor tamaño, mejor calidad y con un diseño en 3D. Por último, se modifica el formato completo del último plano, añadiendo una imagen de fondo y superponiendo letras y números con un aspecto más tradicional.

Tras todos estos novedosos cambios en su imagen, nos volvemos a preguntar la misma cuestión anteriormente planteada, ¿cómo introducir en una cabecera de 16 segundos de duración la misma banda sonora, y que se sincronice el plano final con el último motivo musical? La solución se halla en acortar justo a la mitad la banda sonora, suprimiendo la aparición del primer tutti orquestal y enlazando, de forma extraordinaria, los primeros compases de las trompetas con la segunda repetición del tutti de carácter conclusivo. De esta forma, vuelven a conseguir su objetivo publicitario, apoyar el número de No-Do con el motivo musical (F1). 
Asimismo, vuelven a introducir la percusión anotada por Parada, la cual solo apareció en la primera cabecera de 1943 (F2). Igualmente, surgen dos acordes finales (F1) nunca escuchados hasta ahora, siendo los protagonistas y los que acompañen al plano final en todas las cabeceras de los Noticiarios siguientes.

Como podemos observar en la cabecera $\mathrm{n}^{0} 926(\mathrm{~F} 4)$, vuelven a introducir el plano en negro, ahora acompañado por el motivo final de Parada para que el número de No-Do sea sincronizado con los dos últimos acordes (F1) de la banda sonora.

Tres años más tarde, en 1963, los montadores del No-Do, realizan una nueva cabecera. El cambio es radical respecto a todas sus antecesoras, conteniendo en ella una carga importante de realismo psicológico que afecta directamente al espectador revelando lo que el Régimen quería mostrar en aquel momento.

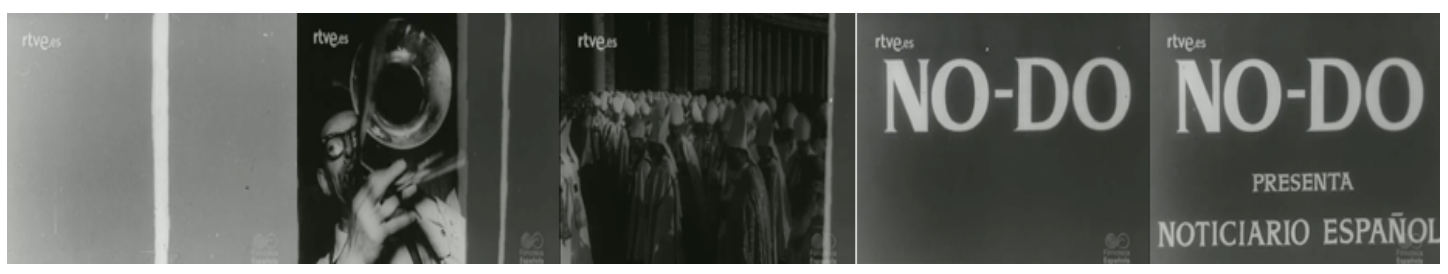

F5. Cabecera No-Do $n^{o} 1058$ A/B/C, 15 de abril 1963, $5^{\text {a }}$ mod. Filmoteca Española.

A pesar de lograr un formato radicalmente diferente, la música sigue siendo la misma. Es en esta cabecera, donde volvemos a confirmar que todos los cambios acontecidos en la imagen se realizaron en función de la duración, forma, ritmo, dinámicas e instrumentación sonora. Toda la agógica musical se tiene en cuenta a la hora de reinventar una cabecera para los Noticiarios.

Existen nuevos elementos significativos que debemos destacar, por un lado, el fundido en negro es sustituido por una apertura de cortinilla la cual, sirve de enlace entre los planos de la cabecera que en ella suceden. En ellos, encontramos temas referentes a la música y la festividad, la representación de la mujer flamenca, los avances tecnológicos, el deporte y el Estado. Igualmente, la figura de la iglesia vuelve a estar presente. Por otro lado, y centrando nuestra atención en los planos finales, el número de No-Do desaparece por completo, algo insólito sabiendo de la importancia publicitaria que tenía para este, y el cual siempre ha estado presente en las cabeceras, de tal forma que es reemplazada por nuevos planos que presentan una sincronía extraordinaria con la música. Este hecho, será conservado hasta su próxima modificación en 1967, del cual desconocemos la razón de la supresión durante casi 4 años de ese plano final. Ahora, 
encontramos los cuatros compases finales (F1) de la banda sonora trabajando juntos en sincronía, empleando cada acorde para una secuencia diferente. Así, cada letra del logotipo $\mathrm{N}-\mathrm{O}-\mathrm{D}-\mathrm{O}$ es apoyada por un acorde musical. De esta forma, consiguen resaltar con la sincronización el logotipo con la misma música de hace 20 años.

Cinco años más tarde, el 1 de enero de 1968, volvemos a tener un nuevo cambio radical en el formato de la cabecera. Donde el logotipo del No-Do concurre con un fondo en movimiento, en concreto, una carretera.

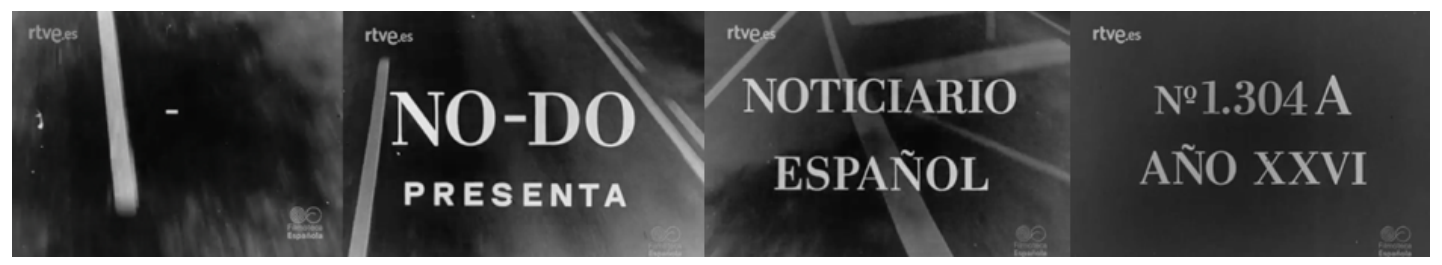

F6. Cabecera No-Do no 1304 A, 1 de enero 1968, 6ª mod. Filmoteca Española.

Estas nuevas secuencias no son creadas casualmente, ya que es en ese mismo año, 1968, donde la creación de autopistas se va fomentando en nuestro país. Si en los años anteriores al régimen le interesaba jugar con las imágenes de la festividad y el deporte, ahora resultaba adecuado mostrar los avances en transporte logrados por el gobierno.

Manteniendo una duración estándar de 18 segundos con sus antecesoras, la cabecera se centra en el logotipo del No-Do, apareciendo y desapareciendo con un fondo en movimiento. Todas las letras del logotipo son sincronizadas con la música del maestro Parada, siendo aprovechada cada nota, ritmo y compás como recurso publicitario. Asimismo, vuelven a introducir el número de catalogación al final de la cabecera, sincronizado de nuevo con los dos últimos acordes (F1) del motivo musical de Parada.

Este nuevo diseño de la cabecera solo duró unos meses durante 1968, ya que el 7 de octubre de ese mismo año realizan dos modificaciones importantes y sustanciales en la imagen. Se diseñó una cabecera para cada catalogación con un aspecto menos cinematográfico y más publicitario: una para la catalogación A y otra para la B, pertenecientes a los No-Dos 1344 A y 1344 B (F7). Por primera vez, aparece el logotipo de "Revista Cinematográfica Española”. 


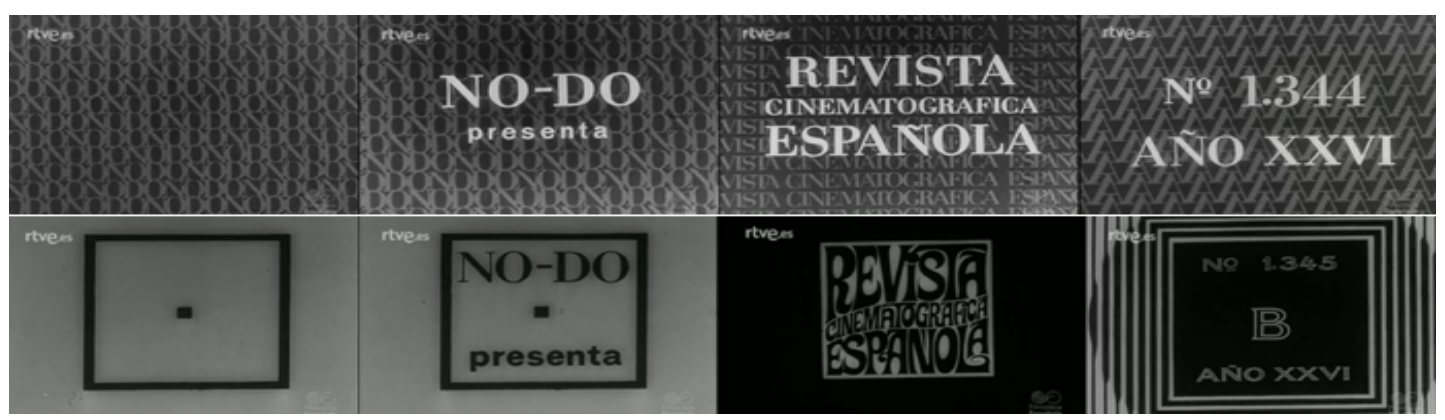

F7. Cabecera No-Do $n^{\circ} 1344$ A y 1344 B, 7 de octubre 1968, $7^{\text {a }}$ mod. Filmoteca Española.

Debemos aclarar que el análisis musical y cinematográfico que a continuación tiene lugar, está basado sobre las cabeceras no 1345 A/B del 14 de octubre de 1968, ya que los fallos audiovisuales que contienen las cabeceras 1344 A/B no permiten un estudio más exhaustivo. De esta forma, el análisis se realiza sobre una cabecera que no contiene problemas ni en el audio, ni la imagen.

Volviendo al análisis de esta nueva cabecera, debemos resaltar que las sincronizaciones de imagen-música que en ellas suceden se realizan de manera precisa, pero conteniendo un error que afecta directamente a la comunicación con el espectador: todas las sincronizaciones, a excepción del último plano, que vuelve a ser acompañado por los dos últimos acordes (F1) de Parada, se efectúan con las partes débiles de los compases de la banda sonora, perdiendo así efectividad y protagonismo.

Hasta 1971 se mantienen estas dos nuevas cabeceras para cada catalogación. No será hasta el año siguiente, el 3 de enero de 1972, cuando podamos presenciar un mismo montaje para las dos partes A/B, concretamente en el Noticiario $\mathrm{n}^{\mathrm{O}} 1513$ (F8).

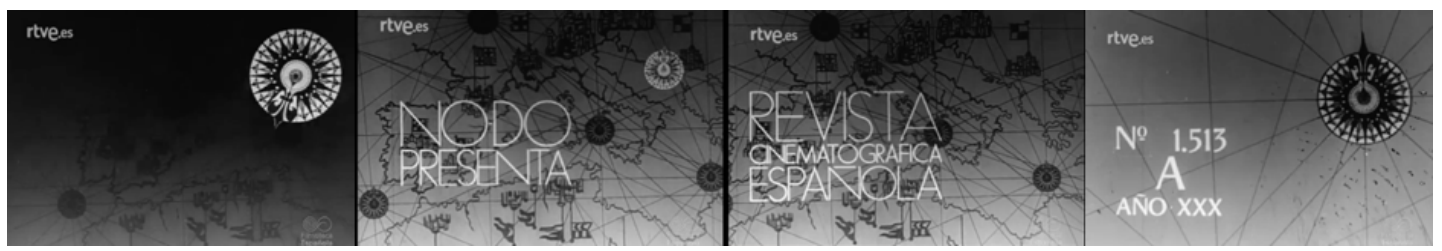

F8. Cabecera No-Do $n^{o} 1513$ A/B, 3 de enero 1972, $9^{\text {a }}$ mod. Filmoteca Española.

Nos encontramos ante el diseño que reúne lo mejor de todo las acontecido hasta 1972. Con una escenografía totalmente artificial, vuelve el mapa cartográfico para el fondo, ahora más detallado en sus figuras geométricas. Asimismo, encontramos un nuevo diseño más usual para el logotipo del No-Do. Todas estas características prueban que la cabecera se aleja de lo puramente cinematográfico 
y se centra en lo publicitario con el único objetivo de la promoción y difusión del Noticiario. Respecto a la sincronía con la música de Parada, nos encontramos ante una de las introducciones que mejor utilizan este recurso como elemento promocional. Por un lado, la aparición de la brújula del primer plano es apoyado en sincronía con el redoble de percusión, y acto seguido, el logotipo de No-Do es sincronizado en cada movimiento. Por otro lado, y como no podía ser de otra forma, todas las secuencias aparecen en sincronía para llegar a la secuencia final, acompañada una vez más, por los dos últimos acordes (F1) de Parada. Debemos añadir, que todos los cambios que transcurren en 1972, ocurren de igual forma hasta 1977, con la única diferencia de que la imagen es emitida en color, hasta su cierre en 1981.

En suma, comprobamos y confirmamos cómo todas las modificaciones sufridas en el Noticiario de No-Do, de 1943 hasta 1981, se producen en función de la música compuesta por el compositor cinematográfico Manuel Parada de la Puente, la cual no fue modificada en 40 años de emisión.

\section{A modo de conclusión}

La música compuesta en las cabeceras de los Noticiarios de No-Do desde 1943, pone de manifiesto la importancia de realizar un gran diseño sonoro para una imagen que se quiere publicitar, promocionar y divulgar.

Tras un profundo análisis de los Noticiarios de No-Do publicados en la Filmoteca de Rtve, y el manuscrito de la banda sonora compuesta para sus cabeceras, digitalizado por la Biblioteca Nacional de España, llegamos a la conclusión de que la realización de dicha composición musical fue un componente comunicativo muy importante para que el fin alcanzado en el No-Do se pudiese cumplir, la difusión de la imagen corporativa de los Noticiarios y Documentales.

Como hemos podido comprobar, no es una simple casualidad que la fanfarria fuera la seleccionada para acompañar la imagen corporativa de No-Do. La elección de los ritmos y melodías creadas para las cabeceras cinematográficas son claves para el funcionamiento y desarrollo publicitario del Noticiario.

En primer lugar, evidencia cómo la utilización de los instrumentos musicales usados en esta construcción musical, la fanfarria, tienen un alto poder para la 
comunicación. Así, vemos cómo la composición de la cabecera utilizada en los Noticiarios del No-Do se asemeja a las imponentes introducciones musicales que estaban creadas para compañías cinematográficas como Universal Pictures, Warner Bross y la 2oth Century Fox. De este modo se constata que el compositor, Manuel Parada de la Puente, tuvo un acercamiento musical a las composiciones realizadas para la cinematografía americana.

En segundo lugar, mediante el análisis comparativo de las diez modificaciones que encontramos en las cabeceras de los Noticiarios desde 1943 a 1981, comprobamos cómo todos los cambios en la imagen fueron realizados en función de la música, mantenida en los 40 años de emisión del No-Do. El montaje de los nuevos planos introducidos tienen como objetivos principales establecer el binomio imagen-música cómo elemento publicitario del No-Do y la sincronización a la perfección del último plano perteneciente a la numerología del Noticiario con los últimos compases de la banda sonora, aspecto sumamente importante para la divulgación del No-Do. Así, formado por 4 compases musicales, encontramos cómo desde el No-Do ${ }^{\circ}{ }^{0} 1$ del 3 de enero de 1943, hasta el Noticiario $\mathrm{n}^{0} 925$ del 26 de septiembre de 1960, son utilizados los tres primeros compases de esta composición, para que, posteriormente, y desde el No-Do $\mathrm{n}^{\mathrm{o}}$ 926 del 3 de octubre de 1960, hagan uso de solo el último compás, utilizado para el número de No-Do hasta el final de su emisión en 1981.

La elección de un breve compás musical, interpretado por una sola clase de instrumento y utilizado en un plano concreto durante la emisión de los Noticiarios, es un alarde de los montadores cinematográficos del No-Do por promocionar, publicitar y difundir los Noticiarios. Es un hecho constatado que añadir una fuente sonora para una imagen, repetida a lo largo del tiempo, crea un efecto recordatorio de la imagen en el espectador y en el oyente, el cual, con solo escuchar esa breve melodía, proyecta de forma inconsciente la imagen a la que está ligada.

De este modo, podemos constatar que el No-Do fue uno de los precursores de la publicidad cinematográfica en nuestro país, siendo pioneros en lo que actualmente se conoce como Audio Branding, disciplina de la comunicación que realiza un diseño sonoro para una determinada imagen.

Por consiguiente, y dejando pensamientos ideológicos y/o políticos aparte, 
debemos reconocer que el No-Do se convierte en un elemento cinematográfico fundamental para comprender y entender el uso del binomio imagen-música como herramientas para la publicidad y difusión del mensaje que quiere transmitir el contenido cinematográfico.

\section{Referencias bibliográficas}

Eguizábal, R. (2011). Historia de la publicidad. Madrid: Fragua.

Guijarro, T. \& Muela, C. (2003). La música, la voz, los efectos y el silencio en publicidad. La creatividad en la producción del sonido. Madrid: Dossat 2000.

Martínez, Ma A. \& Gómez, A. (2015). La imagen cinematográfica: manual de análisis aplicado. Madrid: Síntesis.

Melendo, A. (2011). Introducción al análisis cinematográfico. Córdoba: UCO.

Miranda, L. (2011). Manuel Parada y la música cinematográfica española durante al franquismo: estudio analítico. Tesis Doctoral, Universidad de Oviedo, España, Oviedo.

Spehr, G. (2009). Audio Branding - all new? En Bronner, K. \& Hirt, R., Audio Branding: Brands, Sound and Communication (pp. 27-33). Magdeburgo, Alemania: Nomos.

Ubik media. (2013). Audio Branding. ¿̇A qué suena tu marca? Recuperado de http://www.ubikmedia.net/es/blogcatala/98-audio-branding-a-quesuena-tu-marca 